\title{
Commentary: Aggression and impulsivity after head injury
}

\author{
R. R. Jacobson
}

The most taxing behavioural complications of severe head injury for relatives include irritability and aggression, as illustrated by J. B. Longitudinal studies show an increase over time in the frequency and severity of temper outbursts (Brooks et al, 1986; Hall et al, 1994), which take the form of explosive or impulsive aggression. I will comment on the nature and treatment of impulsive aggression as illustrated in case J. B., emphasising the interaction of neurobiology with motivational, situational and personality factors.

There is no satisfactory nosology of human aggression. Some theorists focus on overt aggressive acts; some on combinations of personality and EEG abnormalities (Monroe, 1978); and others on traits a person high in activity, emotionality and impulsivity is likely to be aggressive (Buss \& Plomin, 1975); while Eichelman \& Hartwig (1990) have developed a database-generated multiaxial approach, encompassing DSM diagnosis and psychological, biological and social axes. Monahan \& Steadman (1994) focus on the risk of harm to others. They argue for the inclusion of subject factors (including dispositional, historical and clinical aspects), together with victim and situational factors, with special note of the interaction or conditional effects between them.

Plutchik \& van Praag (1995) present a processing model of aggression, in which triggers (threat, challenge, insult) lead to an aggressive impulse which then interacts with subject's current constellation of risk factors ('amplifiers') and modulators ('attenuators') (Table 1) to generate the probability of action. Sufficiently probable action will lead to overt behaviour, which in turn generates a risk of violence or of self-harm, which feeds back to the original trigger. Before the head injury, J.B. had five risk factors for the translation of aggressive impulse to action, and he had a history of at least two subtypes of aggression - premeditated and impulsive.

Aggressive outbursts that result from organic brain dysfunction are thought to have characteristics sufficiently typical to suggest an 'organic aggressive syndrome' (Silver \& Yudofsky, 1995) (Box 1).
Table 1. Amplifiers and attenuators of aggres-

sion (adapted from Plutchik \& van Praag, 1995)
Amplifiers

Learning difficulties

Childhood abuse

Conduct disorder

Access to weapons

Mistrust

Trait impulsivity

Abnormal mental state

Brain damage

High arousal

Alcohol and drugs

Victim behaviour

Situational factors
Attenuators

Timidity

High self-control

Victim behaviour, e.g. appeasement

Social support limit-setting

Compliance with treatment or care
Situational factors, e.g.

These features of aggression are similar to those of Elliot's (1992) 'episodic dyscontrol syndrome', a behaviour of doubtful syndromal validity (Lucas, 1994). Episodic dyscontrol behaviour arises not only in organic syndromes, but also in psychoses

Box 1. Features of organic aggression (adapted from Silver \& Yudofsky, 1995)

Reactive - triggered by modest or trivial stimuli

Severity-out of proportion to precipitating stress or provocation

Non-purposeful - no obvious goal served

Explosive - build-up is not gradual; hairtrigger response to provocation; tends to 'feed on itself'

Response to incoming stimuli during outburst - none or irrational

Periodic - the agent lacks self-control to refrain from repetition (after an interim of relative calm)

Ego-dystonic - remorse after outbursts

Robin Jacobson is Consultant Neuropsychiatrist and Senior Lecturer in Puerperal and Mood Disorders at St George's Hospital Medical School (Department of General Psychiatry, Jenner Wing, Cranmer Terrace, London SW17 ORE). He is also Chair of the Basic Sciences Panel, Education Sub-Committee at the Royal College of Psychiatrists. His main research interests include drug treatment of resistant affective disorders, treatment of puerperal disorders and or neuropsychiatric complications of head injury. 
and personality disorders (Mungas, 1983). Barratt (1992) described the same phenomena, which he labelled 'impulsive aggression', in violent prisoners without known organic disorders. Moreover, it is not only impulsive aggression in organic disorders that may respond to carbamazepine, but also impulsive aggression in personality and psychotic disorders, often independently of EEG and neuropsychological status (Mattes, 1984; Gardner \& Cowdry, 1986).

\section{Impulsivity}

Psychologists suggest two broad bipolar components to the dimension of impulsivity: resisting urges $v$. giving in to urges, and responding immediately to a stimulus $v$. planning before making a move (Plutchik \& Van Praag, 1995). Psychiatrists, on the other hand, emphasise impulsive behaviours (e.g. bulimia, pyromania, the addictions) or components of disorders (e.g. frontal lobe syndrome). Impulsivity interacts with other personality traits: thus a person who is high on impulsivity and low on control often reveals erratic and impulsive behaviour, while another who scores highly on both impulsivity and control measures might suffer severe conflict that is not often overtly expressed.

Impulsive aggression appears to require a minimal trigger, to be insensitive to current modulating factors, and to feed positively back to the trigger or impulse.

\section{The relationship between impulsivity and aggression}

Recent studies suggest that long-standing psychological abnormality and environmental stresses or cues may be necessary for the development of violent impulses. When such impulses occur, their control may relate to trait impulsivity (Barratt, 1993), a history in boys with childhood hyperactivity, impulsivity, inattention (Farrington, 1995), or brain dysfunction (through organic disorder or substance abuse or both).

About 30\% of the variance of 'pure' aggression measures is accounted for by 'pure' impulsivity indices (Stein et al, 1993).

Common to both impulsivity and selected forms of aggression are: genetic predisposition; acting without thinking; poor attentional fixity; low serotonin levels; an inability to control selected behaviours despite a vow to do so; frontal lobe dysfunction; and a possible response to anticonvulsants. The associations are likely to differ for impulsivity and aggression (Plutchik \& van Praag, 1995). Psychophysiological studies reveal altered evoked response potentials in certain impulsive aggressive subjects compared with controls, but the findings are heterogeneous in aggressive subjects (Stein et al, 1995).

Case J. B. exhibited multiple risk factors for aggression before his head injury, and is likely to have continued his aggressive behaviour in any event. If he had had no risk factors for aggression, but become purely impulsive after his head injury, he might have shown bulimia, sexual disinhibition, overspending or heavy drinking but not particularly aggression. The marked susceptibility of the frontal and temporal lobes to traumatic brain injury reveals a neurological substrate for acquired impulsivity (as well as reduced planning, selfcontrol and abstract reasoning). In J. B.'s case this has combined with trait impulsivity (reflected in his learning difficulties and conduct disorder) to lower further his threshold for aggression. Alcohol is a notorious facilitator of aggression after head injury, increasing risk of arrest and contributing to poor outcome.

\section{Management}

Management begins with a risk assessment (Grounds, 1995; Moore, 1995). J. B.'s brief aggression towards nurses, his aggressive 'catastrophic' reaction to psychological testing, and his assaults on an old lady were observations made by different professionals and had different time courses; hence the importance of a multi-disciplinary assessment of risk.

Treatment consists of general and behavioural measures and consideration of drugs. Before embarking on treatment for aggressive behaviour, a behavioural analysis is required to elicit specific cues or inadvertent rewards of the behaviour. The antecedents, behaviours and consequences of J.B.'s aggression were documeted. If there is no improvement or behavioural analysis is too difficult, pharmacotherapy may then be required.

Drugs are widely used (and commonly misused) in the management of patients with aggression after head injury. The use of drugs should be considered in two categories: the treatment of any underlying clinical disorder (such as depression in J. B.); and the treatment of aggression. There is no satisfactory classification of aggression which can predict which patient is most likely to respond to the principal classes of drugs listed as beneficial in Table 2. In the treatment of chronic or impulsive aggression, the choice of medication is often guided by the underlying hypothesised mechanism 
Table 2. Psychopharmacology of aggression after head injury (adapted from Ratey \& Gordon, 1993; Dolan \& Coid, 1993; Silver \& Yudofsky, 1995)

\begin{tabular}{|c|c|c|}
\hline Agent & Indications & Comments \\
\hline Antipsychotics & Psychotic symptoms & $\begin{array}{l}\text { Over-sedation and akathisia may increase } \\
\text { aggression }\end{array}$ \\
\hline SSRIs & $\begin{array}{c}\text { Depressive symptoms; irritability; } \\
\text { emotional lability; impulsivity }\end{array}$ & May respond to subnormal doses \\
\hline $\begin{array}{l}\text { Anticonvulsants - } \\
\text { carbamazepine; valproate }\end{array}$ & $\begin{array}{l}\text { Associated seizures; impulsive } \\
\text { agression; 'episodic dyscontrol' }\end{array}$ & Sedation; hepatotoxicity \\
\hline Lithium & $\begin{array}{l}\text { Manic symptoms; emotional } \\
\text { lability; learning disability }\end{array}$ & Neurotoxicity and confusion \\
\hline Benzodiazepines & Anxiety symptoms & Risk of paradoxical rage \\
\hline Beta-blockers & $\begin{array}{l}\text { Chronic or recurrent aggression; } \\
\text { high arousal }\end{array}$ & $\begin{array}{l}\text { Latency of } 4-6 \text { weeks; effective in } \\
\text { placebo-controlled trials }\end{array}$ \\
\hline Buspirone (5- $\mathrm{HT}_{1 \mathrm{~A}}$ agonist) & Anxiety or depressive symptoms & Delayed onset of action \\
\hline $\begin{array}{l}\text { Psychostimulants - methyl- } \\
\text { phenidate; pemoline }\end{array}$ & $\begin{array}{l}\text { If history of attention deficit/ } \\
\text { hyperactivity disorder }\end{array}$ & \\
\hline Anti-androgens & Reduce sexual aggression in certain & \\
\hline
\end{tabular}

of action (i.e. effects on serotonin; kindling, arousal etc.), or by associated symptoms (e.g. antidepressants for depression, or antipsychotics in those with paranoid misinterpretation). A partial response after a specific drug should lead to consideration of adjunctive treatment with a drug that has a different mechanism of action.

\section{Behavioural treatment and other measures}

The general management of aggressive behaviour begins with the identification of warning signals and documenting its antecedents, behaviours and consequences. The psychosocial aspects of the treatment of aggression after head injury are crucial and may be a prerequisite for beneficial pharmacological effect. Family support and training are essential. Behavioural treatment of aggression includes aggression replacement techniques, such as differential reinforcement of other or incompatible behaviours, communication skills training and the programming of activities. Aggression decelerative techniques include calming pre-violent patients; and time-out, which is effective in violent patients immediately after incidents (see Corrigan et al, 1993). Therapeutic community approaches, although sometimes useful with violent offenders, have not been examined in organic aggressive patients. Box 2 summarises helpful behavioural and general measures.
The multifactorial aetiology of J. B.'s aggression suggests that he may respond to anticonvulsants, SSRIs (both for impulsive aggression and depression), abstinence from alcohol, structuring of activities, and multi-agency care. While the case for a care manager in relatively uncomplicated head injury is unproven, it would seen to be essential for patients like J. B. The rational

Box 2. Behavioural and general measures in the treatment of organic aggression

Cognitive-behavioural approaches - aggression replacement by differential reinforcement; assertiveness training; activity programming; communication skills training; promotion of competence in other areas; token economy

Aggression decelerative techniques - social extinction; time out; other measures

Family support - control of alcohol consumption; support and educate relatives and carers; service delivery and coordination; care manager

Measures to decrease specific vulnerability to - stress; loss of support; lack of structure; symptomatic or cognitive decompensation 
management of aggression after head injury benefits from multiaxial evaluation and will almost certainly be multi-disciplinary and collaborative. The continuation of family therapy, drug treatment, behavioural measures and social support is often required into the long term.

\section{References}

Barratt, E. S. (1992) Impulsiveness and aggression. In Violence and Mental Disorder: Developments in Risk Assessment (eds J. Monahan \& H. Steadman), pp. 61-79. Chicago, IL: University of Chicago Press.

- (1993) The use of anticonvulsants in aggression and violence. Psychopharmacology Bulletin, 29, 75-81.

Brooks, N., Campsie, L., Symington, C., et al (1986) The five year outcome of severe blunt head injury: a relative's view. Journal of Neurology, Neurosurgery and Psychiatry, 49, 764-770.

Buss, A. \& Plomin, R. (1975). A Temperament Theory of Personality Development. London: Wiley-Interscience.

Corrigan, P. W., Yudofsky, S. C. \& Silver, J. M. (1993) Pharmacological and behavioural treatments for aggressive psychiatric inpatients. Hospital and Community Psychiatry, 44, 125-133.

Dolan, B. \& Coid, J. (1993) Psychopathic and Antisocial Personality Disorders. Treatment and Reasearch Issues. London: Gaskell.

Eichelman, B. \& Hartwig, A. (1990) The Carolina nosology of destructive behaviour. Journal of Neuropsychiatry, 2, 288-296.

Elliott, F. A. (1992) Violence, the neurological contribution: an overview. Archives of Neurology, 49, 595-603.

Farrington, D. P. (1995) The development of offending and antisocial behaviour from childhood: key findings from the Cambridge Study in Delinquent Development. Journal of Child Psychology and Psychiatry, 36, 909-964.

Gardner, D. L. \& Cowdry, R. W. (1986) Positive effects of carbamazepine on behavioural dyscontrol in borderline personality disorder. American Journal of Psychiatry, 143, 519-522.

Grounds, A. (1995) Risk assessment and management in clinical context. In Psychiatric Patient Violence - Risk and Response (ed. J. Crichton), pp 43-59. London: Duckworth.

Hall, K., Karzmark, P., Stevens, M., et al (1994) Family stressors in traumatic brain injury: a two-year follow-up. Archives of Physical Medicine and Rehabilitation, 75, 876-884.

Lucas, P. (1994) Episodic dyscontrol: a look back at anger. Journal of Forensic Psychiatry, 5, 371-407.

Mattes, J. A. (1984) Psychopharmacology of temper outbursts: a review. Journal of Neroous and Mental Disease, 174, 464-470.

Moore, B. (1995) Risk Assessment: A Practitioner's Guide to Predicting Harmful Behaviour. London: Whiting and Birch.

Monahan, J. \& Steadman, H. J. (1994) Towards a rejuvenation of risk assessment research. In Violence and Mental Disorder Developments in Risk Assessment (eds J. Monahan \& H. J. Steadman), pp. 1-17. Chicago, IL: University of Chicago Press.

Monroe, R. R. (1978) Brain Dysfunction in Aggressive Criminals. Lexington, MA: Lexington Books.

Mungas, D. (1983) An empirical analysis of specific syndromes of violent behaviour. Journal of Nervous and Mental Disease, 171, 354-361.

Plutchik, R. \& van Praag, H. M. (1995) The nature of impulsivity: definitions, ontology, genetics and relations to aggression. In Impulsivity and Aggression, vol. 1 (eds E. Hollander \& D. J. Stein), pp. 7-24. Chichester: John Wiley.

Ratey, J. J. \& Gordon, A. (1993) The psychopharmacology of aggression: toward a new day. Psychopharmacology Bulletin, 29, 65-73.

Silver, J. M. \& Yudofsky, S. C. (1995) Organic mental disorders and impulsive aggression. In Impulsivity and Aggression, vol 15 (eds E. Hollander \& D. J. Stein), pp. 242-259. Chichester: John Wiley.

Stein, D. J., Towey, J. \& Hollander, E. (1995) The neuropsychiatry of impulsive aggression. In Impulsivity and Aggression, vol. 7 (edited by E Hollander \& D J Stein), pp. 91-1-5. Chichester: John Wiley.

- Hollander, E., \& Liebowitz, M. R. (1993) Neurobiology of impulsivity and the impulse control disorders. Journal of Neuropsychiatry and Clinical Neuroscience, 5, 9-17.

\section{Multiple choice questions}

1. With regard to episodic dyscontrol behaviour:

a alteration of consciousness during dyscontrol occurs in over two-thirds of cases

b EEG abnormalities are specific

c carbamazepine reduces outbursts mainly in patients with EEG abnormalities

d aggression is triggered by significant stimuli

e beta-blockers have been shown to be effective in placebo-controlled trials.

\section{Impulsivity:}

$a$ is associated with slow cognitive tempo

b accounts for over $50 \%$ of aggressive

behaviour in the general population

c has a high heritability

$\mathrm{d}$ is reduced by SSRIs

$\mathrm{e}$ is reduced by $5-\mathrm{HT}_{1 \mathrm{~A}}$ agonists.

\section{Aggression after head injury:}

a usually has a gradual build-up

b does not respond to time-out procedures

c rarely depends on situational factors

d responds to carbamazepine only in patients with associated seizures

e is facilitated by higher levels of alcohol than those consumed before the injury.

MCQ answers

$\begin{array}{lll}\text { 1 } & \text { 2 } & 3 \\ \text { a F } & \text { a F } & \text { a F } \\ \text { b F } & \text { b F } & \text { b F } \\ \text { c F } & \text { c T } & \text { c F } \\ \text { d F } & \text { d T } & \text { d F } \\ \text { e T } & \text { e F } & \text { e F }\end{array}$

